\title{
Profiling of Microbial Contamination in Internal Atmosphere of Hospital Ward
}

\author{
AP Pawar ${ }^{1}$, Vividha Dhapte ${ }^{2}$, Vijay Kalrao ${ }^{3}$, Isha Godha ${ }^{1}$, John Jacob ${ }^{1}$ and Asawari Raut ${ }^{1 *}$ \\ ${ }^{1}$ Department of Clinical Pharmacy, Bharati Vidyapeeth University, India \\ ${ }^{2}$ Department of Pharmaceutics, Bharati Vidyapeeth University, India
}

${ }^{3}$ Department of Pediatrics, Bharati Hospital and Research Centre, India

*Corresponding author: Asawari Raut, Department of Clinical Pharmacy, Bharati Vidyapeeth University, Poona College of Pharmacy, Erandwane, Pune-411038, Maharashtra State, India

Submission: 海 February 02, 2018; Published: 梅 May 11, 2018

\begin{abstract}
Background: Indoor air is the greatest propagating source of pathogenic microbes which causes significant contamination in the indoor hospital environment, principally in terms of nosocomial infections. Hence, microbiological testing is necessary to assess air contamination in indoor air of hospital.
\end{abstract}

Objective: The present study was undertaken to assess air contamination in different wards of the hospital to obtain a causative relationship between air contamination and risk of developing infections through microbiological testing.

Method: Microbiological sampling was performed in indoor environment of different wards namely pediatric ward, maternity ward, labor room, pediatric intensive care unit (PICU) and neonatal intensive care unit (NICU) of Bharati Hospital, Pune. Settle plate method was selected wherein McConkey's Agar plates were used for isolation of Gram-negative bacteria, one of the pathogenic groups. The petri plates were then exposed for an hour in different wards and incubated at $37^{\circ} \mathrm{C}$ for 24 hours. After incubation, the total colony forming units (CFU) were counted.

Results: It was found that highest CFU was present in the labor room. As compared to other petri dishes, $18 \pm 3 \mathrm{Gram}$-negative bacteria colonies were seen in the labor room petri dishes. Presence of such contamination in labor room may occur due to improper ventilation and improper sanitization. During each labor, large amount of blood as well as amniotic fluid along with other body fluids are being spilled in the room which plays a significant role in promoting the growth of microorganisms irrespective of whether the mother had any infection during the labor.

Conclusion: Microbiological air contamination testing depicted that the labor room was the most contaminated ward. Proper ventilation and sanitization in the hospital wards with regular quality control would overcome the probability of hospital nosocomial infections thereby promoting safety of mother and infant health.

Keywords: Nosocomial infections; Microbiological Testing; Labor Room; Gram-negative bacteria

Abbreviations: PICU: Pediatric Intensive Care Unit; NICU: Neonatal Intensive Care Unit; CFU: Colony Forming Units; HAIs: Hospital Acquired Infections; MDR: Multi-Drug Resistant; UTI: Urinary Tract Infection

\section{Introduction}

Good air quality is very important especially in health care setting that involves a large number of people. Such settings that are of great concern include hospitals, pathological laboratories, microbial testing units, and cGMP manufacturing units [1]. Maintenance of indoor air quality in hospitals and medical centers has become a critical part of hospital management protocols. Air is the greatest dissemination agency of pathogenic microbes which cause significant problem in the indoor hospital environment, particularly in terms of nosocomial infections or hospital acquired infections (HAIs) [2]. Nosocomial infections are HAIs which are non-existing in the patient at the time of hospital admission. The prevalence rate of HAIs in developed countries such as United States and Swiss hospitals is $6-10 \%$ and $5-10 \%$ respectively $[1,3]$. As it is, $5 \%$ of all patients who go to hospitals for treatment will develop an infection during their hospital stay. This is because the density of pathogens is greater in hospitals than in most other environments. Indeed it has been estimated that the airborne route of transmission accounts for between 10 and $20 \%$ of endemic nosocomial infections [4]. Air borne transmission is known to be the route of infections for diseases and as reported, there is presence of $42.6 \%$ of Grampositivecocci and 14\% Gram-negative rods in hospital air [5,6]. Approximately $10 \%$ of the nosocomial infections in both immunecompromised and healthy people are caused by airborne bacteria 
[7]. Although the cause-and-effect relationship between airborne pathogen levels and nosocomial infections is yet not established, it could be hypothesized that lowering the level of these pathogens in the air would result in providing an environment that would help decrease the risk of nosocomial infections in hospital. Insufficient ventilation, high dusting, overcrowd, aerosols spread through sneezing and coughing, high movement of personnel and improper validation of hospital units as well as equipments are the main sources of indoor air contamination [8]. Indoor hospital air contains diverse microbial population which is responsible for nosocomial infections.

Nosocomial infections can cause urinary tract infections (UTIs), severe pneumonia and infections of other parts of the body. This risk of nosocomial infections is further escalated by the increasing prevalence of antibiotic-resistant pathogens such as Methicillinresistant Staphylococcus aureus (MRSA) and Vancomycin-resistant Enterococci (VRE) among Gram-positive organisms and multi-drug resistant (MDR) Pseudomonas aeroginosa and Acinetobacter among Gram-negative organisms $[9,10]$. In the tropics, researchers have identified that Gram-negative are the most commonly isolated pathogenic microorganisms from hospital environment $[9,10]$. HAIs produce high morbidity, mortality, economic snags and increased hospital stay. Airborne microorganisms and other sources of contamination in hospitals must be reduced to minimum as many of the people passing through hospital lobbies as well as health care workers could be sensitive to these pathogens. Thus, to maintain the lowest possible airborne microbial levels in hospital lobbies, it is crucial to identify the factors influencing these levels [11].

Evaluation of the quality of air in internal hospital environment can be performed routinely via microbiological sampling techniques. Air sampling of microorganisms is a popular method of conducting microbial examinations as it allows direct evaluation of microbial presence [12].

In the present study, air and surface contamination was measured in different wards of the hospital namely, pediatric ward, maternity ward, labor room, pediatric intensive care unit (PICU) and neonatal intensive care unit (NICU). These wards were targeted as risk of developing infections is higher in these wards. The maternity and pediatric wards were selected as there is movement of large number of personnel and patients with active infections in the wards. Labor room was considered as during each labor, a large amount of blood, amniotic fluid and other body fluids are spilled in the room which plays a significant role in promoting the growth of pathogenic microorganisms irrespective of whether the mother had any infection during the labor [13]. Intensive care units were taken into consideration to assess aseptic conditions in these wards.

\section{Materials and Methods}

\section{Location}

Microbiological sampling was performed in indoor environment of different wards of namely pediatric ward, maternity ward, labor room, PICU and NICU of Bharati Hospital, a tertiary care teaching hospital, Pune.

\section{Sampling}

Sampling was carried out at a busy day time using settle plate method. Agar plates were prepared by suspending 50 grams of McConkey's Agar powder in 1 liter of purified water and mixed thoroughly. The mixture was boiled for 2 minutes to dissolve the powder completely with subsequent autoclaving at $121^{\circ} \mathrm{C}$ and 15 psi pressure for 15 minutes. Autoclaved agar suspension was cooled down at $40-45^{\circ} \mathrm{C}$ and stirred well before pouring into the sterile petri dishes. Petri plates containing autoclaved McConkey's Agar were exposed to air for one hour without informing the hospital cleaning team and the plates were incubated at $37^{\circ} \mathrm{C}$ for 24 hours.

\section{Counting}

The total colony forming units (CFU) were counted using magnifying colony counter.

\section{Result and Discussion}

The study of airborne microorganisms in indoor hospital environments is important to understand the dissemination of airborne microbes particularly the pathogenic ones. It is assumed that the environment where patients are treated has an important impact on their recovery wherein acquired infections may complicate their existing medical conditions $[13,14]$. Patients are exposed to a greater risk in indoor air environment because confined areas contained aerosols and allow them to breed to an infectious level. Therefore, it is of utmost importance to evaluate the quality of indoor air in the hospital environment. Various wards and areas in the gynecology ward are easily prone to microbial contamination owing to the considerable presence of amniotic fluid, blood samples, stem cells, tissues and such other biological fluids which serve to be rich source for microbial breeding. If timely measures and routine microbial control is not maintained, the amplified microbial pathogens may pose a serious threat to the health of mother as well as infant with life-threatening consequences.

Table 1: Commonly observed microorganisms in hospital wards.

\begin{tabular}{|c|c|c|c|c|c|}
\hline Commonly Observed Microorganism & Labor Room & Maternity Ward & Pediatric Ward & PICU & NICU \\
\hline Bacillus subtilis & - & - & - & - & - \\
\hline Escherichia coli & +++ & + & +++ & +++ & + \\
\hline Staphylococcus aureus & - & - & + & - & - \\
\hline Pseudomonas aeroginosa & ++ & + & ++ & +++ & + \\
\hline
\end{tabular}

+ Presence of microbial contamination; - Absence of microbial contamination. 
Microbial profiles of simultaneous cultures obtained from hospitalized patients of the targeted wards (maternity ward, pediatric ward, labor room, PICU and NICU) were as presented in Table 1.

Observations revealed the influential presence of Gramnegative pathogens (Escherichia coli and Pseudomonas aeroginosa) to be more dominant as compared to Gram-positive pathogens (Bacillus subtilis and Staphylococcus aureus) in different wards of Gynecology and Obstetrics department. As seen in Table 1, these Gram-negative pathogens illustrated significant existence in labor room, PICU and pediatric wards.

Patients admitted in these wards are prone to infections such as pneumonia, sepsis, urinary tract infection (UTI) and meningitis owing to catheterization. Catheterization serves as a greatest source for microbial contamination further leading to nosocomial infections. Culture tests conducted during catheterization revealed positive results for Gram-negative microorganisms. Additionally, health care workers and paramedics in hospital wards like the cleaning staff, nursing staff, patient attendants and even the physicians may be the cause of Gram-negative infections [15]. The air handling and ventilation system in a hospital set up goes a long way to determine the microbial load per ward of a given hospital. Probing the airborne microorganisms in the hospital wards is important to understand the distribution of microorganisms and the level of cleanliness in that particular area [16]. Thus, the environment where patients are treated has a vital influence on the recovery of the patients and the spread of HAIs [15,16] (Figure 1).

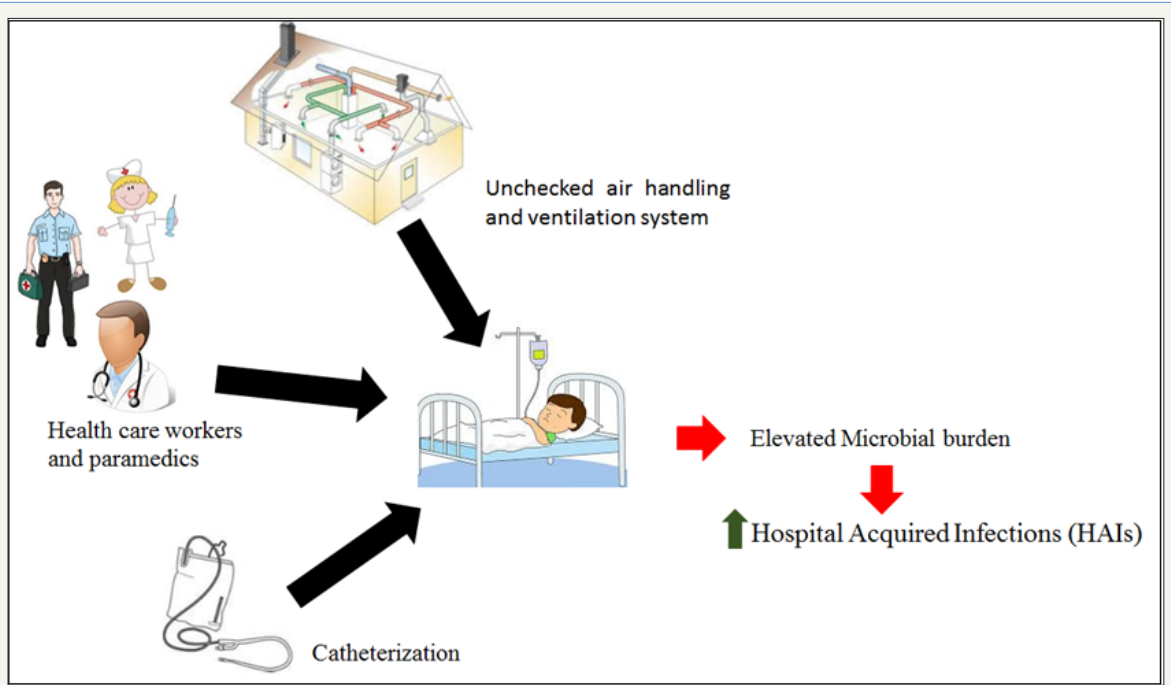

Figure 1: Representative presentation for source of microbial pathogens responsible for HAIs.

The total number of Gram-negative bacterial colonies investigated showed moderately high contamination level present in labor room (Total $18 \pm 3$ CFU) as shown in Figure 2.

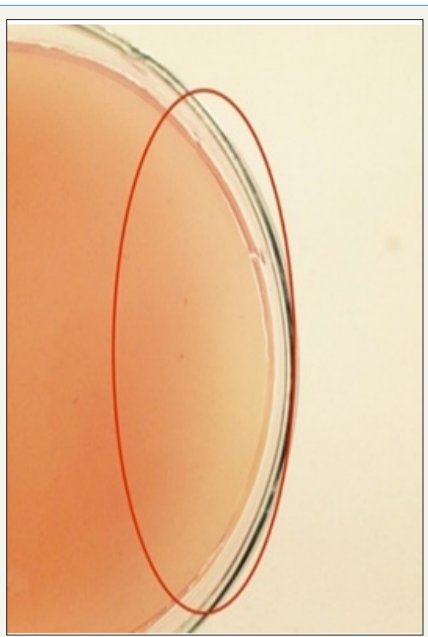

Figure 2: Gram-negative bacterial colonies isolated from labor room.

As during active labor, large amount of biologic fluids (blood, amniotic fluid) is spilled in the room, it serves as a growing medium for microorganisms and hence escalates the risk for nosocomial infections. In the course of labor room visit, it was observed that the labor room was used as a passageway for the health care personnel to enter and exit the room while the procedure was going on which could be another reason correlative of high number of colonies isolated from the labor room $[1,16]$.

Various other contributing factors liable for this level of contamination might be building design, improper ventilation, unrestrained movement of the individuals, high dusting, poor level of public awareness, inadequate health training and limited use of disinfectants [17]. However, these effects are nullified in tertiary care units where the hospital management has to maintain stringent quality standards as per the norms of Medical Council of India (MCI).

Hospital plays a significant role in limiting the spread of common nosocomial infections, the magnitude of which depends on the level of biological fluids, personnel and public movement in the hospital environment [18]. Thus, it is advisable that more frequent quality audits and strict measures should be put in place to check the increasing microbial load in the hospital environment $[18,19]$. This will definitely contribute to rapid recovery of patient 
health and overcome the risk of probable side effects and cross infections [20,21].

\section{Conclusion}

Microbiological air contamination testing confirmed that along with the labor room, PICU and pediatric wards are the most contaminated wards. The indoor unhygienic factor owing to excess biological fluids discharge and unrestricted personnel movement could be responsible for acquiring cross infections to all patients, hospital care personnel and other associated staff. Mostly Gramnegative microorganisms are the major cause of nosocomial infections as depicted in our study. Nosocomial infections produce high morbidity as well as mortality thereby, escalating the cost and length of hospital stay. It is thus, essential to monitor bacteriological load in the indoor air of hospitals and to improve the quality of hospital environment so as to reduce the microbial load. Hospitals should enhance the frequency of good sanitation protocols and infection control measures. Routine auditing of hospital air bioburden is substantially recommended. Thorough hand washing and use of alcohol rubs by medical personnel and public visitors before and after each patient contact would effectively combat nosocomial infections by nullifying the microbial dispersals within the hospital

\section{References}

1. Agbagwa, Obakpororo E, Onyemaechi, Sandra (2014) A Microbiologica quality of indoor air of a general hospital and a health center in Rivers State Nigeria. Int J Curr Microbiol App Sci 3(12): 424-431.

2. Bhatia L, Vishwakarma R (2010) Hospital indoor airborne microflora in private and government owned hospitals in Sagar City. India World J Med Sci 53: 65-70.

3. Ahsanullah M. Mirbahar, Badaruddin A Memon (2005) Bacteriological monitoring through air sampling in different locations of teaching/ civil hospital Sukkur. J App Em Sc 1(2): 13-15.

4. DH Tambekar, PB Gulhane, D D Bhokare (2007) Studies on Environmental Monitoring of Microbial Air Flora in the Hospitals. J Med Sci 7(1): 67-73.

5. Brachman PS (1970) Nosocomial infection- airborne or not? Proceedings of the international conference on nosocomial infections. American Hospital Association pp: 189-192.

6. Greene VW, D Vesley, RG Bond, GS Michaelsen (1962) Microbiological contamination of hospital air. 2. Qualitative studies. Applied Microbiol 10: $567-571$.

7. Gioffre A, Dragone M, Ammoscato I, Iannò A, Marramao A, et al. (2007) The importance of the airborne microorganism's evaluation in the operating rooms: the biological risk for health care workers. G Ital Med LavErgon 29: 743-745
8. Heidelberg JF, Shahamat M, Levin M, Rahman I, Stelma G et al. (1997) Effect of aerosolization on culturability and viability of gram-negative bacteria. Appl Environ Microbiol 63(9): 3585-3588.

9. Mehta G (2000) Microbiological surveillance of operation theatres. New Delhi, India, 10-52.

10. Ping YH, Zhi YS, Chi-Hao C, Walter D, Hui MH, et al. (2013) Airborne and Surface-Bound Microbial Contamination in Two Intensive CareUnits of a Medical Center in Central Taiwan. Aerosol and Air Quality Research 13: 1060-1069.

11. Konar J, Das S (2013) Common contaminants of bacteriology laboratory: Microbiological Paramores. International Journal of Pharmaceutical Science Invention 11(2): 36-37.

12. MF Yassin, S Almouqatea (2010) Assessment of airborne bacteria and fungi in an indoor and outdoor environment. Int J Environ Sci Tech 7(3): 535-544.

13. Spendlove JC, Fannin KF (1983) Source, significance, and control of indoor microbial aerosols: human health aspects. Public Health Rep 98(3): 229-244.

14. Jaffal AA, Banat IM, El Mogheth AA, Nsanze H, Benar A, et al. (1997) Residential indoor airborne microbial populations in the United Arab Emirates. Environ Intern 23(4): 529-533.

15. Ekhaise FO, Isitor EE, Idehen O, Emoghene AO (2010) Airborne Microflora in the Atmosphere of an Hospital Environment of University of Benin Teaching Hospital (UBTH), Benin City, Nigeria. World Journal of Agricultural Sciences 6(2): 166-170.

16. Whyte W (1986) Sterility assurance and models for assessing airborne bacterial contamination. J Parenter Sci Technol 40(5): 188-197.

17. Orpianesi C, Cresci A, La Rosa F, Saltalamacchia G, Tarsi R (1983) Evaluation of microbial contamination in a hospital environment. Comparison between the Surface Air System and the traditional method. Nuovi Ann IgMicrobiol 34(3): 171-185.

18. Leung M, Chan AH (2006) Control and management of hospital indoor air quality. Med Sci Monit 12(3): SR17-23.

19. Ekhaise FO, Ogboghodo BF (2010) Microbiological indoor and outdoor air quality of two major hospitals in Benin City Nigeria. J Biomed Res 169-174.

20. World Health Organization (2002) Guidelines on Prevention and Control of Hospital Associated Infections. Regional Office for South-East Asia New Delhi January 2002.

21. Park DU, Yeom JK, Lee WJ, Lee KM (2013) Assessment of the Levels of Airborne Bacteria, Gram-Negative Bacteria, and Fungi in Hospital Lobbies. Int J Environ Res Public Health 10(2): 541-555.
Creative Commons Attribution 4.0 International License

For possible submissions Click Here

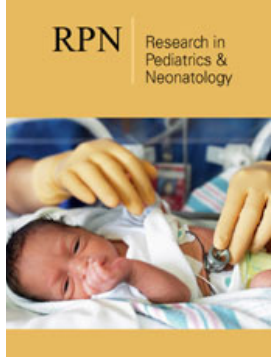

\section{Research in Pediatrics \& Neonatology}

\section{Benefits of Publishing with us}

- High-level peer review and editorial services

- Freely accessible online immediately upon publication

- Authors retain the copyright to their work

- Licensing it under a Creative Commons license

- Visibility through different online platforms 